\title{
Prevalence of Different Types of Barriers to the Use of Glucometer in Diabetic Patients
}

\author{
Abhishek Pradhan ${ }^{1}$, Charutha Reji ${ }^{2}$, A. R. Shabaraya ${ }^{3}$ \\ ${ }^{1}$ Assistant Professor, Department of Pharmacy Practice, ${ }^{2}$ Student, PharmD, Department of Pharmacy Practice, \\ ${ }^{3}$ Professor and Head, Department of Pharmacy Practice, \\ Srinivas College of Pharmacy, Mangalore, Karnataka- 574143
}

Corresponding Author: Charutha Reji

\begin{abstract}
Self-monitoring of blood glucose (SMBG) is a very useful method for patients with diabetes to maintain glycaemic control. Different types of barriers in glucometer use of diabetic patients include the high cost of strips, pain, lack of knowledge and motivation, need of assistance and lack of inventory supplies of glucometer. The purpose of the study was to access the prevalence of different types of barriers to the use of glucometer in diabetic patients. A prospective observational study involving 150 diabetic patients was conducted at a Dakshina Kannada from January 2021 to June 2021. The study was conducted among patients of both genders having Type 1 and Type 2 Diabetes mellitus. A total of 150 patients participated in our study qualifying the inclusion criteria. The main factors influencing the glucometer use was related to its cost, pain, lack of knowledge and supply. The barriers found were mainly the cost of the strips, fear for needles, pain, lack of knowledge and motivation, need of assistance and lack of inventory supplies of glucometer. Participants insight to the purpose of glucometer use, complexity, cost, pain related to glucometer as well as educating, catering knowledge and motivation were the key factors taken care by the health care professionals while advising the patients having diabetes mellitus with SMBG.
\end{abstract}

Keywords: Self-monitoring blood glucose level (SMBG), Diabetes mellitus (DM).

\section{INTRODUCTION}

Self-monitoring of blood glucose (SMBG) is a tool that enhances self-care among people with diabetes ${ }^{[1]}$. Nowadays, Diabetes mellitus is a challenging public problem that is most of the elderly persons are suffering from diabetes. A glucometer is a medical device for determining the approximate concentration of glucose in the blood. SMBG allows people with diabetes to undertake the necessary interventions to help improve their health outcomes. For people with Type 2 diabetes using insulin, benefit of SMBG in improving glycemic control is well established. SMBG helps people with diabetes to detect hypoglycaemia and to adjust their insulin dosage approximately. This self-monitoring of blood glucose (SMBG) is considered one of the cornerstones of diabetes care and is useful for maintaining near normal blood glucose levels, providing feedback to the healthcare provider and to the patient regarding therapeutic effectiveness, helping patients adjust insulin dosage, diet and exercises and aiding in the detection and prevention asymptomatic hypoglycaemia and extreme hyperglycemia.

The barriers identified includes the frustration related to high blood glucose reading, fear of pain due to needle prick, cost of strips, unavailability of strips, inconvenience in use, lack of knowledge, motivation and self-efficacy. To overcome the barriers, the patients should stick on to right schedule by fixing a best time to check 
and be adherent, trying to prick the sides of ones fingers, and retain inventory so that one has a complete set at different locations, educating the patients about the use of glucometer in controlling the blood sugar levels.

Therefore, this study aimed to explore the barriers among people with diabetes. This may help health care providers and the authorities to improve the utilization of SMBG to provide strict glycemic control.

\section{METHODOLOGY}

The present study was a community based, prospective and observational to identify, resolve and prevent the barriers to use of glucometer in patients with diabetes mellitus in different regions of Dakshina Kannada district. The study was conducted for a duration of 6 months from January 2021 to June 2021.The present study included 150 participants based on qualifying the inclusion criteria. The study protocol was approved by the Institutional Ethics Committee (IEC) Srinivas Institute of Medical Science and Research Centre (SIMS \& RC), Mukka, Mangaluru. The patients greater than 18 years of age, belonging to both gender with Type 1 and Type 2 diabetes mellitus and willing to participate in the study were included in the study. Patients with age less than 18 years of age, terminally ill and not willing to participate were excluded from the study. Data for the study were collected using data collection form from the patients. The materials used were questionnaires, data collection forms, patient information leaflet (PIL).

Statistical Analysis involved collecting and scrutinizing all data samples and finally collected data were analyzed using Microsoft Excel 2010.

\section{RESULTS}

\section{DEMOGRAPHIC DETAILS OF THE STUDY PARTICIPANTS}

A total of 150 patients participated in our study. $45.33 \%$ of participants were males and $54.67 \%$ of patients were females. The highest percentage of age group was $51-70$ years $(76.6 \%)$ followed by $71-90$ years $(16 \%)$ and age group of 31-50 years $(7.3 \%)$. Of the total, $24 \%$ has elementary school education, were $33.3 \%$ high school pass outs, and $42.6 \%$ were college/ university graduates.

Table 1. Demographic details of the study participants

\begin{tabular}{|l|l|l|}
\hline Characteristics & Number & Percentage (\%) \\
\hline Gender & & \\
\hline Male & 68 & 45.3 \\
\hline Female & 82 & 54.6 \\
\hline Age (in years) & & \\
\hline $31-50$ & 11 & 7.3 \\
\hline $51-70$ & 115 & 76.6 \\
\hline $71-90$ & 24 & 16 \\
\hline Educational level & & \\
\hline Elementary school & 36 & 24 \\
\hline High school & 50 & 33.3 \\
\hline College/ university & 64 & 42.6 \\
\hline
\end{tabular}

\section{Cost of strips and needles}

Cost was the main reason for the participants not practicing SMBG regularly. $84.67 \%$ experienced high cost of strips and needles and $15.33 \%$ were not affected by it.

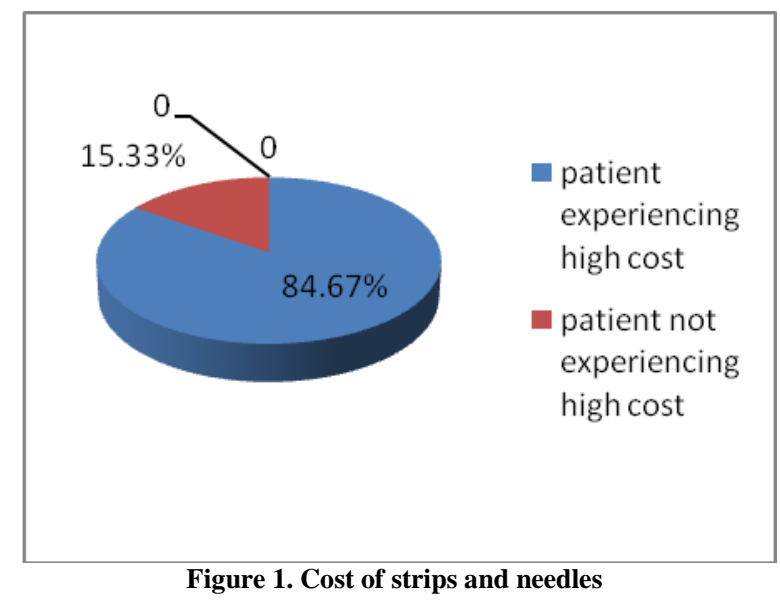

\section{Lack of motivation}

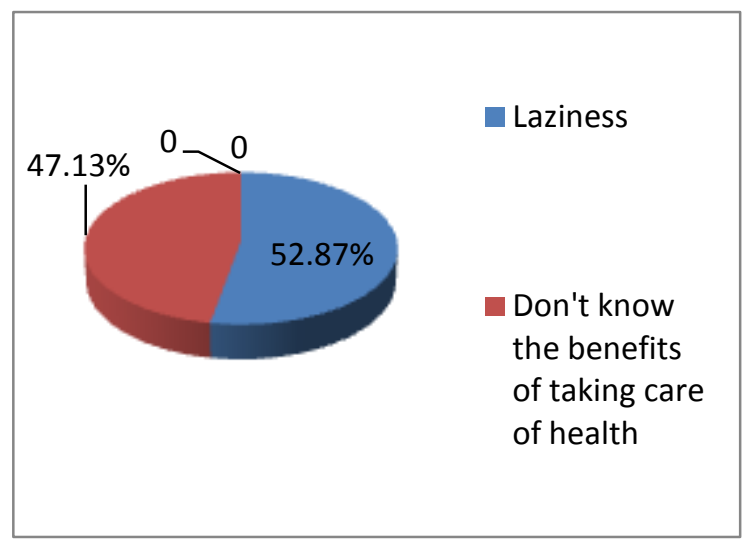

Figure 2. Lack of motivation 
Lack of motivation reported by the participants, $70.67 \%$ experienced lack of motivation in which $52.87 \%$ of patients were lazy to use glucometers and $47.13 \%$ don't know the benefits of taking care of health.

\section{Lack of knowledge}

Participants often considered frequent SMBG as unnecessary, and this changed the way they have monitored their blood glucose levels. $72.67 \%$ of patients had lack of knowledge and were unaware of how to use the glucometer and $27.33 \%$ know how to use it.

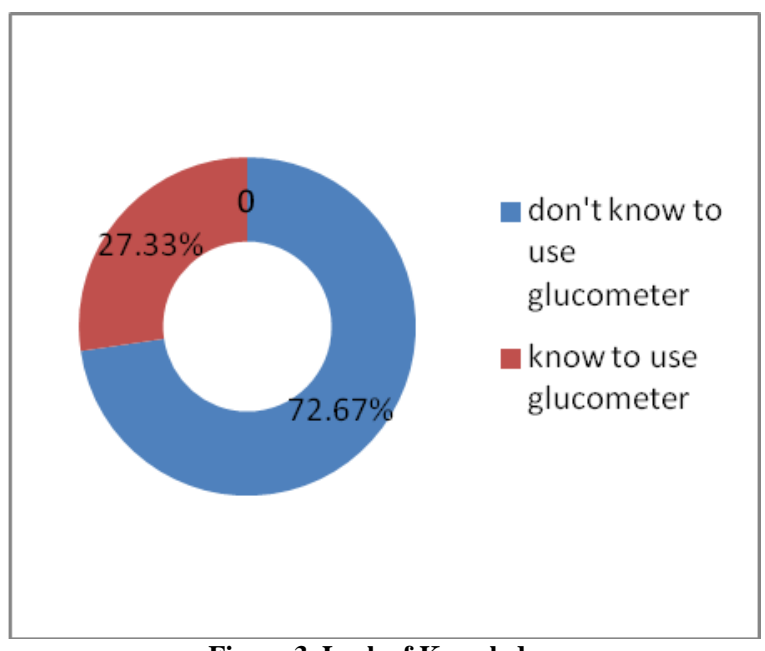

Figure 3. Lack of Knowledge

\section{Pain while using glucometer}

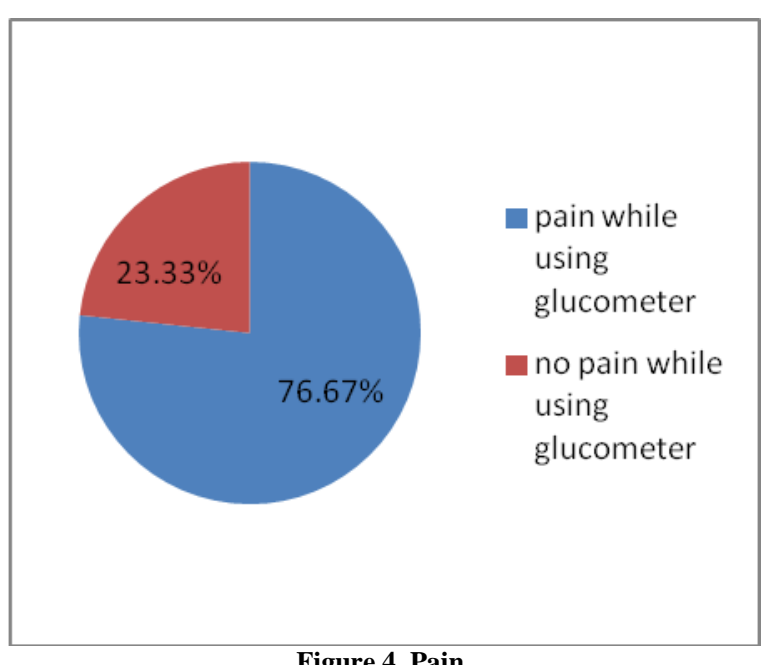

Participants found the fingertip pricking painful and hence did not practice SMBG. Among 82 subjects, 76.67\% patients had pain while using glucometers and $23.33 \%$ did not experience pain.

\section{Need of assistance}

Out of 82 patients, $23.08 \%$ assisted by physicians, $6.59 \%$ assisted by nurses, $57.14 \%$ assisted family members and $13.19 \%$ needed friends for glucometer use.

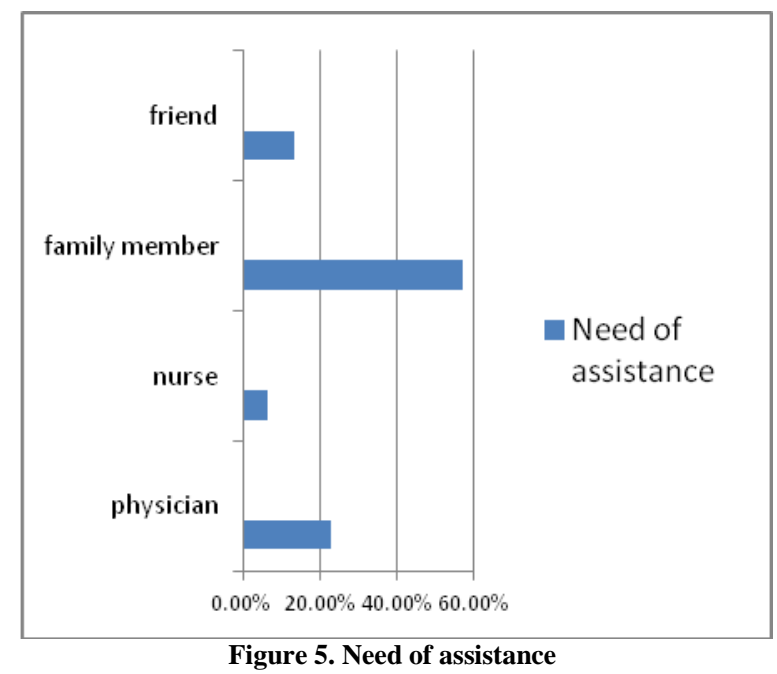

\section{Lack of supply in glucometers}

Out of 150 patients, $84.67 \%$ experienced lack of supply in which $37 \%$ were having poor income, $25.98 \%$ had lack of glucometer supply, $17.32 \%$ had long distance to hospital/pharmacy and $19.68 \%$ had busy work schedules.

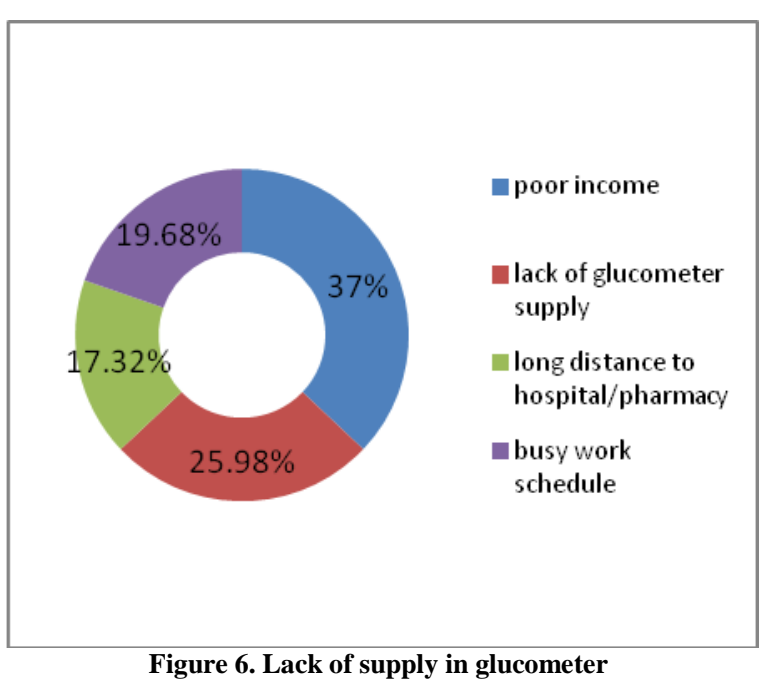

\section{Lack of data interpretation}

Among 150 patients, $54.67 \%$ doesn't know how to interpret the data given on glucometer and $45.33 \%$ patients know to interpret the data. 
Table 2. Types of Barriers

\begin{tabular}{|c|c|c|}
\hline Barriers & Number of participants experiencing(N) & Percentage (\%) \\
\hline Cost of strips and needles & 127 & $84.67 \%$ \\
\hline pain & 115 & $76.67 \%$ \\
\hline Fear of needles & 74 & $49.33 \%$ \\
\hline $\begin{array}{l}\text { Lack of supply } \\
\text { Poor income } \\
\text { Lack of glucometer } \\
\text { Long distance to hospital/pharmacy } \\
\text { Busy work schedule }\end{array}$ & $\left.\begin{array}{l}47 \\
33 \\
22 \\
25\end{array}\right\} 127$ & $\begin{array}{l}37.00 \% \\
25.98 \% \\
17.32 \% \\
19.68 \% \\
\end{array}$ \\
\hline $\begin{array}{l}\text { Lack of motivation } \\
\text { Laziness } \\
\text { Don't know the benefits of taking care of health }\end{array}$ & $\left.{ }_{50}^{56}\right\}_{106}$ & $\begin{array}{l}52.83 \% \\
47.17 \%=70.67 \%\end{array}$ \\
\hline $\begin{array}{l}\text { Need of assistance } \\
\text { Physician } \\
\text { Nurse } \\
\text { Family member } \\
\text { Friend }\end{array}$ & $\left.\begin{array}{l}21 \\
6 \\
52 \\
12\end{array}\right\} 91$ & $\begin{array}{l}23.08 \% \\
6.59 \% \\
57.14 \%=60.67 \% \\
13.19 \%\end{array}$ \\
\hline Lack of data interpretation & 82 & $54.67 \%$ \\
\hline Lack of knowledge & 109 & $72.67 \%$ \\
\hline
\end{tabular}

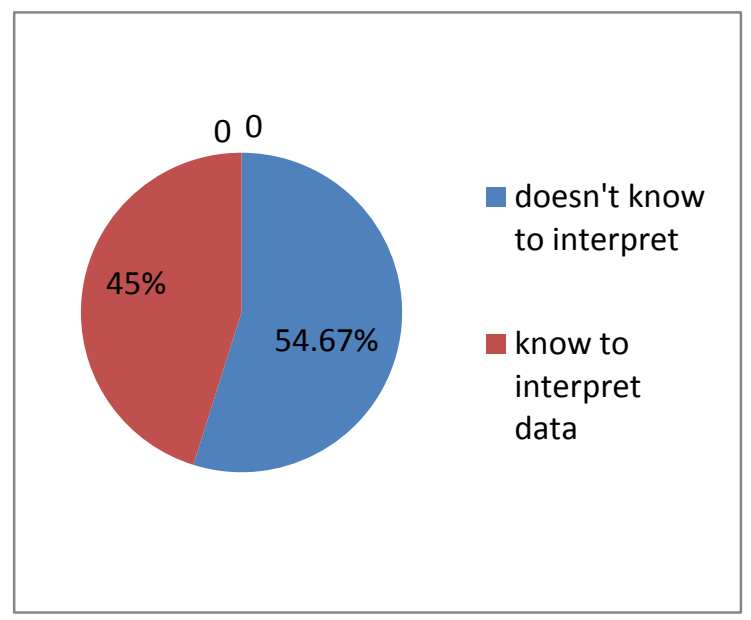

Figure 7. Lack of data interpretation

\section{DISCUSSION}

A total of 150 patients participated in the present study. $45.33 \%$ of participants were males and $54.67 \%$ of patients were females. The highest percentage of age group was $51-70$ years $(76.6 \%)$ followed by 71-90 years $(16 \%)$ and age group of 31-50 years $(7.3 \%)$. Of the total, $24 \%$ has elementary school education, were $33.3 \%$ high school pass outs, and $42.6 \%$ were college/university graduates.

A study by Woong WM et al., performed on the primary care clinic of a teaching hospital in Malaysia was to explore the barriers and facilitators to SMBG in people with Type2 diabetes. Participants highlighted a range of found that the fingertip pricking painful and high cost hence did not practice SMBG that frequently ${ }^{[1]}$. Similarly our study stated that, out of the total 150 subjects, $68 \%$ experienced high cost of strips and needles and perceived barriers to their utilization of SMBG. These included the cost of test strips and needles, fear of needles and pain. The cost of SMBG was the main reason why participants did not practice SMBG regularly.64\% patients had pain while using glucometers while $36 \%$ did not had pain.

A study by Tenderich A et al., Significant motivation among people with diabetes mellitus to learn to use their meters in a productive way to identify and treat high and low blood glucose levels and to make meaningful lifestyle changes. Patients who were not getting right education or motivation to be empowered to check their blood glucose levels ${ }^{[5]}$.Comparably, $58 \%$ experienced lack of motivation in which $52.87 \%$ of patients were lazy to use glucometers and $47.13 \%$ don't know the benefits of taking care of health in the study.

A study by Woong WM et al., Participants often considered frequent SMBG as unnecessary which caused them to change the way they have monitored their blood glucose levels based on their own perceived needs ${ }^{[1]}$. Similarly in our study, $63.33 \%$ of patients had lack of knowledge and were unaware of how to use the glucometer and $36.67 \%$ and $54.67 \%$ doesn't know how to interpret the data given on glucometer.

A study by Johnson JL et al., Perceived behavioural control barriers were poor income levels, lack of glucometers, 
busy work schedule and long distance to hospitals or pharmacy ${ }^{[4]}$. Likewise our study, $84.67 \%$ experienced lack of supply in which $37 \%$ were having poor income, $25.98 \%$ had lack of glucometer supply, $17.32 \%$ had long distances to hospitals/ pharmacy and $19.68 \%$ had busy work schedule.

\section{CONCLUSION}

The main benefit of SMBG is to help people with diabetes in order to improve their glycemic control. In order to enhance adherence to SMBG, the barriers to SMBG and their prevalence were explored through their perspectives. The present study concluded that cost and pain were the common barriers to SMBG. Out of the total 150 subjects, $68 \%$ experienced high cost of strips and needles and $78 \%$ experienced pain while using glucometer.

Subsidies for test strips and needles would help to ease the financial burden for people with diabetes and this would increase their adherence to SMBG. Health care providers should teach techniques for making the finger prick less painful, for instance using the lateral of the finger, avoiding use of thumbs and index fingers, or using shallower needle depths. It is recommended that health care providers improve awareness in people with diabetes through appropriate education regarding the benefits of SMBG in diabetes control.

The health authorities concerned should consider providing financial incentives to encourage more frequent monitoring of blood glucose levels. Pain related to SMBG, as well as personal motivations were the other key factors that health care providers must consider when advising people with diabetes to conduct SMBG.

Acknowledgement: None

Conflict of Interest: None

Source of Funding: None

\section{REFERENCES}

1. Woong WM, Chua SS, Ng CJ. Barriers and facilitators to self-monitoring of blood glucose in people with type 2 diabetes using insulin: a qualitative study. Patient preference and adherence. 2014; 8: 237.

2. Karter AJ, Ferrara A, Darbinian JA, Ackerson LM, Selby JV. Self-monitoring of blood glucose: language and financial barriers in a managed care population with diabetes. Diabetes care. 2000; 23(4): 47783.

3. Adu MD, Malabu UH, Malau-Aduli AE, Malau-Aduli BS. Enablers and barriers to effective diabetes self-management: A multi-national investigation. PloS one. 2019; 14(6): 0217771.

4. Johnson JL, O'Neal KS, Pack CC, Carter SM. Barriers to Patient Use of Control Solution for Glucose Meters: Surveys of Patients, Pharmacists, and Providers in a Metropolitan Area. Journal of Diabetes Science and Technology. 2017; 11(3): 55357.

5. Tenderich A. Use of blood glucose meters among people with type 2 diabetes: patient perspectives. American diabetes association. 2013; 26(2): 67-70.

6. Cabral CP, Parente EB, Freire PV, Yamaya AC, Schnoll C, Simões VR et al., Main barriers on glucometer utilization during physician's appointment of insulin users T2D patients: In Diabetology \& Metabolic Syndrome. 2005; (Vol. 7, No. S1, p. A201). BioMed Central.

7. Mogre V, Johnson NA, Tzelepis F, Paul C. Barriers to diabetic self-care: A qualitative study of patients' and healthcare providers' perspectives. Journal of clinical nursing. 2019; (11-12): 2296-308.

8. Adams, A.S., Mah, C., Soumerai, S.B. et al. Barriers to self-monitoring of blood glucose among adults with diabetes in an HMO: A cross sectional study. BMC Health Serv Res 3, 6 (2003).

9. Mastura I, Mimi O, Piterman L, Teng CL, Wijesinha S. Self-monitoring of blood glucose among diabetes patients attending government health clinics.Med J Malaysia.2007;62(2):147-151.

10. Snoek FJ, Malanda UL, de Wit M. Selfmonitoring of blood glucose: psychological barriers and benefits. Eur Diabetes Nurs.2008;5(3):112-115. 
11. Hortensius J, Kars MC, Wierenga WS, Kleefstra N, Bilo HJ, van der Bijl JJ.Perspectives of patients with type 1 or insulin-treated type 2 diabetes on selfmonitoring of blood glucose:a qualitative study. BMC Public Health. 2012;12:167177.

12. Nagelkerk J, Reick K, Meengs L. Perceived barriers and effective strategies to diabetes self-management. J Adv Nurs. 2006;54(2): 151-158.

13. Peel E, Douglas M, Lawton J. Selfmonitoring of blood glucose in type 2 diabetes: longitudinal qualitative study of patients' perspectives. BMJ. 2007; 335 (7618): 493-496.

14. Green J, Thorogood N. Qualitative Methods for Health Research. 2nd ed. London: SAGE Publications Ltd; 2009.

15. Vincze G, Barner JC, Lopez D. Factors associated with adherence to selfmonitoring of blood glucose among persons with diabetes. Diabetes Educ. 2004;30(1): $112-125$.

16. Zgibor JC, Simmons D. Barriers to blood glucose monitoring in a multiethnic community. Diabetes Care. 2002;25(10): 1772-1777.

17. Jones PM, Remley C, Engberg RA. Development and testing of the barriers to self-monitoring blood glucose scale. Diabetes Educ. 1996;22(6):609-616.

18. Kirk JK, Graves DE, Bell RA, Hildebrandt CA, Narayan KM. Racial and ethnic disparities in self-monitoring of blood glucose among US adults: a qualitative review. Ethn Dis. 2007;17(1):135-142.

19. Palmer AJ, Dinneen S, Gavin JR, Gray A, Herman WH, Karter AJ. Cost-utility analysis in a UK setting of self-monitoring of blood glucose in patients with type 2 diabetes. Curr Med Res Opin. 2006; 22(5):861-872.

20. Giaccari A, Grassi G, Ozzello A. Selfmonitoring of blood glucose: guideline application rather than utilization restrictions on testing strips has potential to reduce diabetes healthcare costs in Italy. Diabetes Technol Ther. 2012;14(10): 862-867.

21. Nyomba BL, Berard L, Murphy LJ. The cost of self-monitoring of blood glucose is important factor limiting glycemic control in diabetic patients. Diabetes Care.2002; 25(7):1244-1245.

22. Tak-Ying Shiu A, Kwan JJ, Wong RY. Social stigma as a barrier to diabetes selfmanagement: implications for multi-level interventions. J Cli Nurs. 2003;12(1):149150.

23. Heinemann L, Koschinsky T. Clinical application and challenges of blood glucose measurement technology for selfmonitoring. Diabetes Technol Ther. 2008; 10(Suppl 1):S27-S34.

24. Davis WA, Bruce DG, Davis TM. Is selfmonitoring of blood glucose appropriate for all type 2 diabetic patients? The Fremantle Diabetes Study. Diabetes Care. 2006;29(8): 1764-1770.

25. Hughes MD. The business of selfmonitoring of blood glucose: a market profile. J Diabetes Sci Technol. 2009;3(5): 1219-1223.

How to cite this article: Pradhan A, Reji C, A. R. Shabaraya. Prevalence of different types of barriers to the use of glucometer in diabetic patients. Int J Health Sci Res. 2021; 11(9): 181186. DOI: https://doi.org/10.52403/ijhsr. 20210928 